\title{
Article \\ Null Effect of Transcranial Static Magnetic Field Stimulation over the Dorsolateral Prefrontal Cortex on Behavioral Performance in a Go/NoGo Task
}

\author{
Tatsunori Watanabe ${ }^{1}$, Nami Kubo ${ }^{1}$, Xiaoxiao Chen ${ }^{1}$, Keisuke Yunoki ${ }^{1}$, Takuya Matsumoto ${ }^{1,2}$, \\ Takayuki Kuwabara $^{1}$, Toru Sunagawa ${ }^{3}$, Shota Date ${ }^{3} \mathbb{D}$, Tatsuya Mima ${ }^{4}$ and Hikari Kirimoto ${ }^{1, *(\mathbb{D})}$
}

1 Department of Sensorimotor Neuroscience, Graduate School of Biomedical and Health Sciences, Hiroshima University, Hiroshima 734-8553, Japan; twatan@hiroshima-u.ac.jp (T.W.); e.orinoco26@gmail.com (N.K.); d185984@hiroshima-u.ac.jp (X.C.); d205546@hiroshima-u.ac.jp (K.Y.); d203652@hiroshima-u.ac.jp (T.M.); m203434@hiroshima-u.ac.jp (T.K.)

2 Japan Society for the Promotion of Science, Tokyo 102-0083, Japan

3 Department of Analysis and Control of Upper Extremity Function, Graduate School of Biomedical and Health Sciences, Hiroshima University, Hiroshima 734-8553, Japan; torusuna@hiroshima-u.ac.jp (T.S.); sdate@hiroshima-u.ac.jp (S.D.)

4 Graduate School of Core Ethics and Frontier Sciences, Ritsumeikan University, Kyoto 603-8577, Japan; t-mima@fc.ritsumei.ac.jp

* Correspondence: hkirimoto@hiroshima-u.ac.jp

Citation: Watanabe, T.; Kubo, N.; Chen, X.; Yunoki, K.; Matsumoto, T.; Kuwabara, T.; Sunagawa, T.; Date, S.; Mima, T.; Kirimoto, H. Null Effect of Transcranial Static Magnetic Field Stimulation over the Dorsolateral Prefrontal Cortex on Behavioral Performance in a Go/NoGo Task. Brain Sci. 2021, 11, 483. https:// doi.org/10.3390/brainsci11040483

Academic Editors: Leonor J. Romero Lauro and Alex Green

Received: 28 February 2021

Accepted: 9 April 2021

Published: 11 April 2021

Publisher's Note: MDPI stays neutral with regard to jurisdictional claims in published maps and institutional affiliations.

Copyright: (c) 2021 by the authors. Licensee MDPI, Basel, Switzerland. This article is an open access article distributed under the terms and conditions of the Creative Commons Attribution (CC BY) license (https:// creativecommons.org/licenses/by/ $4.0 /)$.
Abstract: The purpose of this pilot study was to investigate whether transcranial static magnetic field stimulation (tSMS), which can modulate cortical excitability, would influence inhibitory control function when applied over the dorsolateral prefrontal cortex (DLPFC). Young healthy adults $(n=8$, mean age $\pm \mathrm{SD}=24.4 \pm 4.1$, six females) received the following stimulations for $30 \mathrm{~min}$ on different days: (1) tSMS over the left DLPFC, (2) tSMS over the right DLPFC, and (3) sham stimulation over either the left or right DLPFC. The participants performed a Go/NoGo task before, immediately after, and $10 \mathrm{~min}$ after the stimulation. They were instructed to extend the right wrist in response to target stimuli. We recorded the electromyogram from the right wrist extensor muscles and analyzed erroneous responses (false alarm and missed target detection) and reaction times. As a result, 50\% of the participants made erroneous responses, and there were five erroneous responses in total $(0.003 \%)$. A series of statistical analyses revealed that tSMS did not affect the reaction time. These preliminary findings suggest the possibility that tSMS over the DLPFC is incapable of modulating inhibitory control and/or that the cognitive load imposed in this study was insufficient to detect the effect.

Keywords: transcranial static magnetic field stimulation; non-invasive brain stimulation; cognitive function; dorsolateral prefrontal cortex; response inhibition; Go/NoGo task

\section{Introduction}

Transcranial static magnetic field stimulation (tSMS) is one of non-invasive brain stimulation (NIBS) tools that can modulate brain activity as well as motor and cognitive functions. Since Oliviero and colleagues reported a reduction of motor cortical excitability after application of tSMS over the motor cortex in 2011 [1], a relatively larger number of studies have been conducted to investigate the effectiveness of this new tool. For example, tSMS has been shown to reduce somatosensory-evoked potentials when applied over the sensorimotor cortex [2-4], and also to increase alpha-band power when applied over the parietal or occipital cortex $[5,6]$. Furthermore, recent studies revealed changes in cortical activity in brain regions apart from the site of stimulation [7-10]. With regard to behavioral parameters, tSMS has been demonstrated to impair performance of difficult reaction time task [5], postural adjustment task [11], and force-matching task [12] when it was applied over the occipital cortex, supplementary motor area, and motor cortex, respectively. 
Moreover, tSMS has an ability to modulate symmetry judgements with the temporal cortex stimulation [13] and to enhance offline learning with the motor cortex stimulation [14], although the enhancement of offline learning by tSMS was not evident in another study [15]. Collectively, even though non-significant changes in sensorimotor cortical excitability by tSMS found in some previous studies should be acknowledged [16,17], tSMS has the potential to induce modulations of various human functions.

Inhibitory control is an important component of executive functions, enabling one to reduce impulsive behavior and to suppress inappropriate responses and actions. When this function is impaired, various kinds of behavioral problems, such as food and smoking urges [18,19], drug and alcohol abuse [20], and hasty decision making [21-23], can occur. From this perspective, a number of studies have examined whether impaired inhibitory control can be rehabilitated using cognitive training or NIBS tools. Particularly, repetitive transcranial magnetic stimulation (rTMS) and transcranial direct current stimulation (tDCS), which either increase or decrease the cortical excitability depending on the stimulation setting, have received a great attention during a past decade as cognitive training has been shown to have a small effect on impulsive behavior in a recent meta-analysis [24]. For instance, excitatory high-frequency rTMS over the left dorsolateral prefrontal cortex (DLPFC), one of brain regions in an inhibitory control network [25], increased accuracy in a Go/NoGo task that assesses proactive inhibitory control in alcohol dependent individuals [26]. Similarly, excitatory anodal tDCS over the left DLFPC increased accuracy in a Go/NoGo task in individuals with major depressive disorder [27]. Interestingly, inhibitory cathodal tDCS over the left DLPFC also increased accuracy in the same task in students with attention deficit hyperactivity disorder (ADHD) [28]. On the other hand, there are also studies reporting non-significant effects of these NIBS techniques on inhibitory control function. For example, Go/NoGo task performance was found not to be affected by anodal tDCS over the left DLPFC in individuals with schizophrenia [29] and with ADHD [30,31]. Furthermore, high-frequency rTMS over the right DLPFC has been demonstrated not to influence Go/NoGo task performance in individuals with alcohol use disorders [32,33]. At present, no firm conclusion has been made as to whether these techniques are effective in treating inhibitory control function of individuals with clinical conditions, and continuous investigation on this topic is warranted to evaluate the clinical use of NIBS techniques, including tSMS.

Accordingly, the purpose of this study was to investigate the effect of tSMS over the DLPFC on behavioral performance in a Go/NoGo task. Static magnetic fields (SMFs) by tSMS have been demonstrated to reduce the cortical excitability [1]. Although the exact mechanism underlying this reduction has not been fully understood, it is proposed that SMFs induce reorientation of membrane phospholipids, which results in deformation of ion channels and their function [34-36]. Since performance of Go/NoGo task was found to be impaired by cathodal tDCS, which reduces the cortical excitability, irrespective of brain side in healthy adults [37,38], we hypothesized that tSMS over the left/right DLPFC would similarly impair performance. If tSMS is capable of modulating the inhibitory control function and thus the DLPFC, it may be used to correct asymmetric activity of the frontal lobes (i.e., hypoactivation in one side and hyperactivation in the other side) observed in individuals with such clinical conditions as major depressive disorder and impulsive behavior.

\section{Materials and Methods}

\subsection{Participants}

Eight healthy adults (mean age $\pm \mathrm{SD}=24.4 \pm 4.1$, six females) participated in this study. They were university students or graduates. Exclusion criteria included a history of neurological and psychiatric disorders. None of them had metal implants or were under medical treatment for any condition. They were all right-handed as confirmed by Edinburgh Handedness Inventory and had normal or corrected-to-normal vision. 


\subsection{Procedure}

A cylindrical $\mathrm{NdFeB}$ neodymium magnet (diameter, $50 \mathrm{~mm}$; height, $30 \mathrm{~mm}$ ) with a surface magnetic flux density of $534 \mathrm{mT}$, maximum energy density of $49 \mathrm{MGOe}$, and a strength of $862 \mathrm{~N}$ (88 kgf) nominal value (NeoMag, Ichikawa, Japan) was used for tSMS. A non-magnetic stainless-steel cylinder of the same size and weight was used for sham stimulation. With the aid of an arm-type lightning stand (C-stand, Avenger, Cassola, Italy), the magnet or sham device was placed over F3 or F4 of international 10-20 system of electrode placement (Figure 1a). The stimulation site for sham stimulation (F3 or F4) was randomized among the participants [13].

(a) Stimulation location

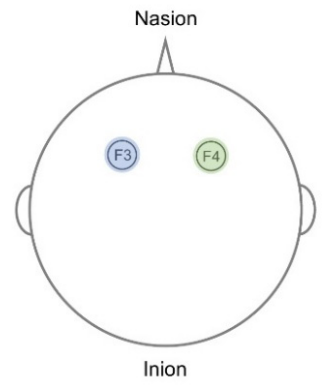

(b) Time course of experiment

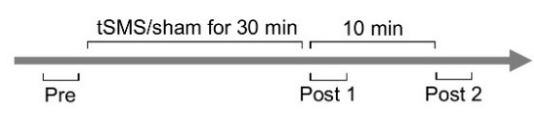

(c) Go/NoGo task

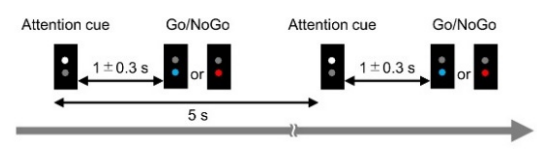

Figure 1. Experimental task and procedure. TSMS or sham stimulation was applied over F3 or F4 of international 10-20 system (a). The performance of Go/NoGo task was evaluated before (pre), immediately after (post 1), and $10 \mathrm{~min}$ after (post 2) tSMS/sham stimulation (b). The participants made a response to a blue light and withheld the response to a red light (Go/NoGo task) (c).

Each of these stimulations was given to all the participants in a random order on different days (at least one day apart), and the stimulation was blinded to the participants (single-blind study). The participants performed a Go/NoGo task before (pre), immediately after (post 1), and $10 \mathrm{~min}$ after (post 2) the stimulation (Figure 1b). The protocol was the same for tSMS and sham.

\subsection{Go/NoGo Task}

A custom-made illumination device with light emitting diodes (LED) (4 Assist, Tokyo, Japan) was used to present visual stimuli (Figure 1c). Trials started with a white LED stimulus (attention cue of $150 \mathrm{~ms}$ ), which was followed by either a blue or red LED stimulus (150 ms) with an interstimulus interval of random duration between 1000 and $1300 \mathrm{~ms}$. The blue LED stimulus served as a target signal (Go), and the red LED stimulus served as a non-target signal (NoGo). The intertrial interval was $5 \mathrm{~s}$. Similar to previous studies [39], 10 target and 10 non-target signals were presented randomly in one block of trials.

The participants sat on a chair comfortably $100 \mathrm{~cm}$ in front of the custom-made illumination device with the pronated right forearm resting on a flat armrest. They were instructed to extend the right wrist as fast as possible when the target stimulus was presented and to withhold the response when the non-target stimulus was presented. Responses to the stimuli were evaluated using electromyogram (EMG) activity recorded from the right wrist extensor muscles.

\section{4. $E M G$}

EMG was recorded from the right wrist extensor muscles. The disposable $\mathrm{Ag} / \mathrm{AgCl}$ electrodes were placed over the right wrist extensor muscles (one-third the distance from the olecranon to the distal head of the ulna) with an interelectrode distance of approximately $2 \mathrm{~cm}$. The signal was amplified (FSE-DEMG1, 4 Assist, Japan), filtered between 5 and $1000 \mathrm{~Hz}$, and digitized at 10k Hz using an A/D converter (PowerLab, AD Instruments, Sydney, Australia). 


\subsection{Data Analysis}

The raw EMG signal was full-wave rectified and averaged over $500 \mathrm{~ms}$ pre-stimulus interval. The activation onset of the right wrist extensor muscles was defined as a time point at which the rectified EMG amplitude exceeded 3SD from the pre-stimulus average. Responses to non-target signals and non-responses to target signals were counted as errors (false alarm and missed target detection).

\subsection{Statistical Analysis}

$\mathrm{R}$ ( $\mathrm{R}$ development team) was used for statistical analysis. We performed a two-way repeated measures analysis of variance (ANOVA) to examine the effect of stimulation (F3, F4, and sham) and time (pre, post 1, and post 2) on reaction times after confirming that they were normally distributed (Shapiro-Wilk test). Greenhouse-Geisser correction was applied when the sphericity assumption was violated. No statistical test was performed for erroneous responses as there were only five erroneous responses in total $(0.003 \%)$. Significant level was set at 0.05 .

\section{Results}

There were five erroneous responses in total $(0.003 \%)$, and $50 \%$ of the participants made no errors at all (Table 1). Figure 2 presents reaction time results. A two-way repeated measures ANOVA revealed no significant main effect of stimulation $\left(\mathrm{F}_{(2,14)}=2.47, p=0.121\right.$, $\left.\eta^{2}=0.024\right)$ or time $\left(\mathrm{F}_{(2,14)}=0.33, p=0.724, \eta^{2}=0.0018\right)$ on reaction times. There was no significant interaction between them $\left(\mathrm{F}_{(4,28)}=0.94, p=0.46, \eta^{2}=0.0066\right)$.

Table 1. The number of erroneous responses in each task session (five in total).

\begin{tabular}{ccccccccc}
\hline \multicolumn{1}{c}{ Erroneous Responses } \\
\hline & Left DLPFC & \multicolumn{3}{c}{ Right DLPFC } & \multicolumn{2}{c}{ Sham } \\
\hline pre & post 1 & post 2 & pre & post 1 & post 2 & pre & post 1 & post 2 \\
1 & 0 & 0 & 1 & 1 & 1 & 1 & 0 & 0 \\
\hline
\end{tabular}

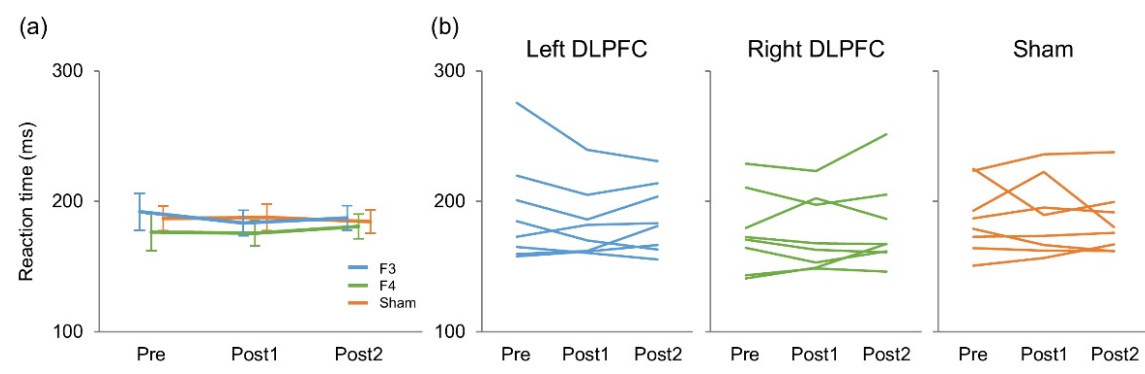

Figure 2. Mean (a) and individual (b) reaction times during Go/NoGo task.

To explore these reaction-time findings in depth, we additionally performed a Bayesian two-way repeated measures ANOVA on the same data using JASP (JASP Team (2020). JASP (Version 0.14.1) (Windows 10)) with the JASP's default prior. This analysis tests whether the experimental data provide stronger evidence for the null or alternative hypothesis, and a Bayes Factor $\left(\mathrm{BF}_{10}\right)<1 / 3$ indicates greater support for the null while a $\mathrm{BF}_{10}>1$ indicates greater support for the alternative [40]. We found that the $\mathrm{BF}_{10}$ for the main effects of stimulation and time were 3.59 and 0.15 , respectively, and that the $\mathrm{BF}_{10}$ for the interaction between these factors was 0.11 . The post-hoc comparisons for the stimulation effect based on the default $t$-test with a Cauchy $(0, \mathrm{r}=1 / \operatorname{sqrt}(2))$ prior provided evidence indicating that the reaction time was faster in $\mathrm{F} 4$ than $\mathrm{F} 3\left(\mathrm{BF}_{10}=6.56\right.$, posterior odds $\left.=3.86\right)$ and sham stimulation condition $\left(\mathrm{BF}_{10}=5.61\right.$, posterior odds $\left.=3.30\right)$ regardless of the time point of measurement (i.e., pre, post 1 , and post 2).

Moreover, to ensure the non-significant interaction, we performed equivalence testing, which can differentiate true negative results from underpowered studies [41-43] using R's 
equivalence package (https:/ / cran.r-project.org/web/packages/equivalence/index.html, accessed on 10 April 2021). Equivalence testing was conducted with a two one-sided test procedure in a pair-wise fashion between different time points of measurement (i.e., pre, post 1 , and post 2) for each stimulation condition. As the effect of NIBS on reaction time in proactive inhibition tasks has been reported to be approximately 20-30 ms [44-46], an equivalent threshold of $20 \mathrm{~ms}$ was considered to be the minimum relevant difference. We found that the difference in reaction time between pre and post 1 , between pre and post 2 , and between post 1 and post 2 was significantly equivalent to zero for all the stimulation conditions $(p<0.05) .95 \%$ confidence intervals are provided in Table 2.

Table 2. 95\% confidence intervals from equivalence testing.

\begin{tabular}{|c|c|c|}
\hline \multirow[b]{2}{*}{$\begin{array}{l}\text { Pre vs. Post } 1 \\
(-0.99,18.44)\end{array}$} & \multicolumn{2}{|l|}{ Left DLPFC } \\
\hline & $\begin{array}{l}\text { Pre vs. Post } 2 \\
(-9.25,18.80)\end{array}$ & $\begin{array}{l}\text { Post } 1 \text { vs. Post } 2 \\
(-11.16,3.26)\end{array}$ \\
\hline \multicolumn{3}{|c|}{ Right DLPFC } \\
\hline $\begin{array}{l}\text { Pre vs. Post } 1 \\
(-7.33,8.90)\end{array}$ & $\begin{array}{l}\text { Pre vs. Post } 2 \\
(-13.47,4.55)\end{array}$ & $\begin{array}{c}\text { Post } 1 \text { vs. Post } 2 \\
(-14.45,3.96)\end{array}$ \\
\hline \multicolumn{3}{|c|}{ Sham } \\
\hline $\begin{array}{l}\text { Pre vs. Post } 1 \\
(-13.66,11.88)\end{array}$ & $\begin{array}{l}\text { Pre vs. Post } 2 \\
(-7.53,12.36)\end{array}$ & $\begin{array}{c}\text { Post } 1 \text { vs. Post } 2 \\
(-7.91,14.52)\end{array}$ \\
\hline
\end{tabular}

To assess stability (individual consistency) of the reaction time over time and across different stimulation conditions, intraclass correlation coefficients (ICC) with a two-way model and absolute agreement were calculated using $\mathrm{R}$ for each stimulation condition as well as for each time point of measurement (i.e., pre, post 1 , and post 2). The analysis showed that the reaction times were consistent within participants over time, with ICC values of $0.87(p<0.001)$ for F3 (left DLPFC), $0.91(p<0.001)$ for F4 (right DLPFC), and $0.82(p<0.001)$ for sham (Figure 3a). Additionally, they were consistent within participants across different stimulation conditions, with ICC values of $0.82(p<0.001)$ for pre, 0.71 $(p<0.001)$ for post 1 , and $0.87(p<0.001)$ for post 2 (Figure $3 b)$. These ICC values indicate that agreement was substantial $(0.60<$ ICC $\leq 0.8)$ or almost perfect $($ ICC $\leq 0.81)$ [47].
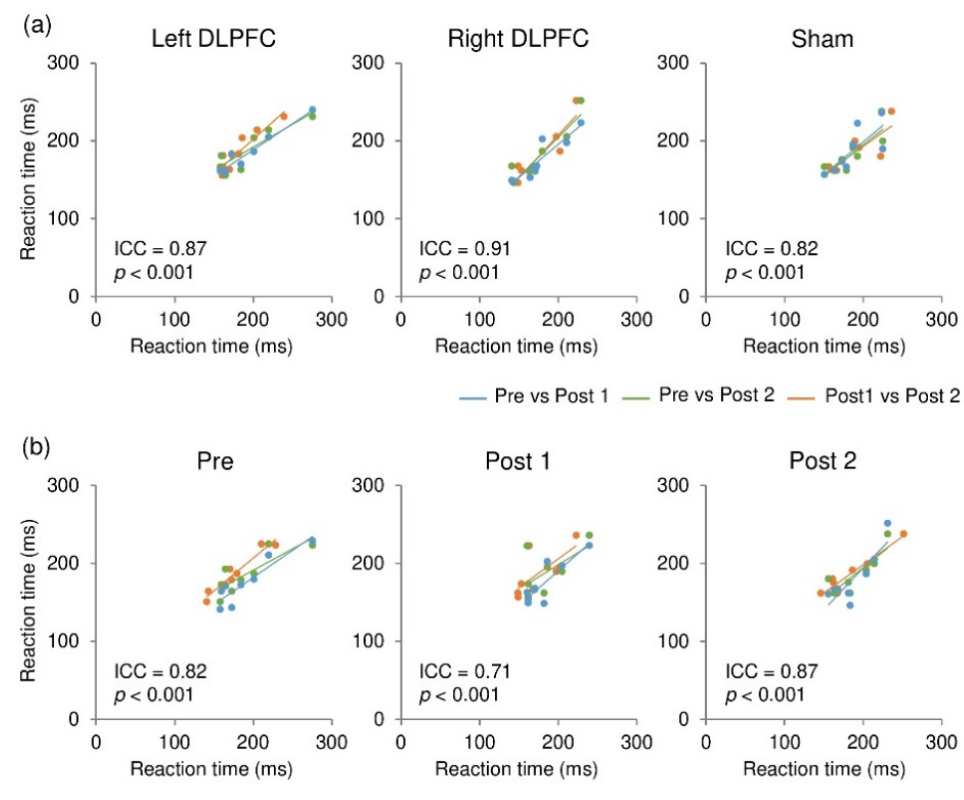

— Lt DLPFC vs Rt DLPFC — Lt DLPFC vs Sham — Rt DLPFC vs Sham

Figure 3. Consistency of reaction times within individuals over time (a) and across different stimulation conditions (b). 


\section{Discussion}

This study examined the effect of tSMS over the DLPFC on response inhibition using a Go/NoGo task. We found that the stimulation affected neither erroneous response nor reaction time. Furthermore, the reaction time was almost perfectly/substantially consistent within individuals over time and across different stimulation conditions. Our findings suggest the possibility that tSMS over the DLPFC is incapable of modulating inhibitory control function and/or that the cognitive load imposed during the task used in this study was insufficient to detect the tSMS effect.

In a Go/NoGo task, a bias toward response execution can result in increased erroneous responses, while a bias toward response inhibition can result in lengthened reaction times [48]. Thus, when the number of erroneous responses is not affected by NIBS, reaction time to the target signal can be expected to change (speed-accuracy tradeoff). Indeed, previous studies have reported that NIBS over the DLPFC did not affect accuracy but reduced reaction time in cognitive tasks in healthy individuals [49-51]. However, in the present study traditional and Bayesian ANOVA both revealed no significant difference in either accuracy or reaction time between different time points of measurement, indicating that tSMS over the DLPFC has no effect on the performance of Go/NoGo task. The subsequent equivalent testing results further support this argument.

There are several explanations that account for our findings. First, tSMS could have not been strong enough to modulate the DLPFC. In previous studies, we and the other group confirmed that $\mathrm{SMF}$ of $\mathrm{NdFeB}$ magnet decreases in inverse proportion to the square of the distance but is strong enough to have biological effects on most surface cortical sites (110-190 $\mathrm{mT}$ at $2-3 \mathrm{~cm}$ from the magnet surface) [2,52]. Additionally, a reduction of cortical excitability by around $20-25 \%$ has been continuously reported in single-pulse TMS and somatosensory-evoked potential experiments [1,2]. However, as mentioned in a review about the effect of tDCS on cognitive function [50], the effect of NIBS (including tSMS) on the prefrontal cortex including the DLPFC may be different from that on the sensorimotor cortex. Furthermore, the effect of NIBS on cognitive function could be in a proportional relationship with its strength. Thus, it is conceivable that SMF of $\mathrm{NdFeB}$ magnet is strong enough to modulate the sensorimotor cortex but not the DLPFC, and it would be interesting to investigate whether the larger $\mathrm{NdFeB}$ magnet has the modulatory effect on the DLPFC in future studies. As an alternative hypothesis, there is a possibility that $\mathrm{tSMS}$ affected brain regions distant from the stimulation site since tSMS applied over the DLPFC has been reported to modulate cortical oscillations not in the DLPFC but in the occipital and frontoparietal cortices [9]. Further studies are warranted to better understand the relationship between tSMS and cognitive functions and their associated brain networks.

Second, it is possible that the task used in the present study was too easy for our participants (i.e., healthy young adults) and did not impose enough cognitive load to recruit the DLPFC strongly. This assumption is supported by our finding of only five erroneous responses in total, and from this view it is reasonable to consider that the DLPFC that is only weakly activated in the first place is unlikely to be modulated by tSMS. According to four recent meta-analyses about the effect of tDCS over the DLPFC on cognitive function $[49,50,53,54]$, accuracy and/or reaction time can be improved with anodal tDCS in neuropsychiatric patients; however, there was a disagreement on these effects in healthy individuals. This potentially indicates that baseline activity level of the DLPFC is one of factors influencing the effect of NIBS on cognitive function. That is, when it is high, it can be lowered using NIBS, and vice versa. With respect to tSMS, response time and erroneous response during a choice reaction time task have been reported to be unaffected by two hours of tSMS over the occipital cortex in healthy adults [55]. Further, a previous study using a visual search task, during which study participants searched for a target in an array containing distractors, demonstrated that an increase in reaction time by tSMS over the occipital cortex occurred selectively in the condition with high difficulty [5]. Therefore, the effect of tSMS over the DLPFC on cognitive function may be apparent with a task that imposes higher cognitive load than the Go/NoGo task used in the present study. 
Third, the site of stimulation may not have been appropriate to modulate the performance of Go/NoGo task. At the level of neural processes, inhibitory control function is mediated by a prefrontal-basal ganglia circuit [56-59] and has been reported to be carried out by two separate networks, one with the DLPFC and the other with the inferior frontal cortex (IFC) [60]. In previous studies, NIBS applied over the IFC was found to influence reactive inhibitory control, that is, to stop already initiated response [61,62] but not proactive inhibitory control [61]. Furthermore, NIBS over the DLPFC was revealed to impact the proactive inhibitory control in such task as Go/NoGo [37,63] and Stroop tasks [64]. From these evidences, the DLPFC and IFC are assumed to be involved in proactive and reactive inhibitory control, respectively. On the other hand, some previous studies provided evidence of proactive inhibitory control being influenced by tDCS over the IFC $[46,65]$. Therefore, although we think it unlikely, performance of Go/NoGo task may have been affected by tSMS over the IFC.

The limitation of this study was the small sample size. Given the equivalence testing results and the almost perfect/substantial consistency of reaction time within participants over time and across different stimulation conditions, increasing the sample size seems unlikely to change our findings. On the other hand, the $\mathrm{BF}_{10}$ supporting the null hypothesis in our Bayesian analysis is categorized as moderate evidence according to Jeffreys's scale [40]. Furthermore, there are a number of studies reporting interindividual variability in response to NIBS $[66,67]$. Therefore, further studies with more representative sample sizes are warranted to advance the field.

\section{Conclusions}

In conclusion, this study suggests two possibilities: (1) tSMS over the DLPFC is incapable of modulating inhibitory control and (2) the cognitive load imposed by the current Go/NoGo task was insufficient to detect the tSMS effect. Further studies are necessary to investigate whether cognitive function is modulated by tSMS in other cognitive tasks or when applied to the other brain regions, to advance our understanding of the effectiveness of this NIBS as a clinical tool.

Author Contributions: Conceptualization, T.W. and H.K.; methodology and investigation, N.K., X.C., K.Y., T.M. (Takuya Matsumoto), T.K. and S.D.; formal analysis, T.W. and N.K.; writing the original draft, T.W.; visualization, T.W.; supervision, T.W., T.S., T.M. (Tatsuya Mima) and H.K.; funding acquisition, T.W., T.M. (Tatsuya Mima) and H.K. All authors have read and agreed to the published version of the manuscript.

Funding: This research was partially supported by grants from the Japan Society for the Promotion of Science (19H01091, 19H03977, and 20K19708).

Institutional Review Board Statement: This study was approved by ethics committee of Hiroshima University (No. C-242) and conducted following Declaration of Helsinki.

Informed Consent Statement: Written informed consent was obtained from each participant after explaining the study procedures.

Data Availability Statement: Data available on request.

Conflicts of Interest: The authors declare no conflict of interest.

\section{References}

1. Oliviero, A.; Mordillo-Mateos, L.; Arias, P.; Panyavin, I.; Foffani, G.; Aguilar, J. Transcranial static magnetic field stimulation of the human motor cortex. J. Physiol. 2011, 589, 4949-4958. [CrossRef] [PubMed]

2. Kirimoto, H.; Asao, A.; Tamaki, H.; Onishi, H. Non-invasive modulation of somatosensory evoked potentials by the application of static magnetic fields over the primary and supplementary motor cortices. Sci. Rep. 2016, 6, 34509. [CrossRef]

3. Kirimoto, H.; Tamaki, H.; Matsumoto, T.; Sugawara, K.; Suzuki, M.; Oyama, M.; Onishi, H. Effect of transcranial static magnetic field stimulation over the sensorimotor cortex on somatosensory evoked potentials in humans. Brain Stimul. 2014, 7, 836-840. [CrossRef] 
4. Kirimoto, H.; Tamaki, H.; Otsuru, N.; Yamashiro, K.; Onishi, H.; Nojima, I.; Oliviero, A. Transcranial Static Magnetic Field Stimulation over the Primary Motor Cortex Induces Plastic Changes in Cortical Nociceptive Processing. Front. Hum. Neurosci. 2018, 12, 63. [CrossRef]

5. Gonzalez-Rosa, J.J.; Soto-Leon, V.; Real, P.; Carrasco-Lopez, C.; Foffani, G.; Strange, B.A.; Oliviero, A. Static Magnetic Field Stimulation over the Visual Cortex Increases Alpha Oscillations and Slows Visual Search in Humans. J. Neurosci. Off. J. Soc. Neurosci. 2015, 35, 9182-9193. [CrossRef] [PubMed]

6. Carrasco-López, C.; Soto-León, V.; Céspedes, V.; Profice, P.; Strange, B.A.; Foffani, G.; Oliviero, A. Static Magnetic Field Stimulation over Parietal Cortex Enhances Somatosensory Detection in Humans. J. Neurosci. Off. J. Soc. Neurosci. 2017, 37, 3840-3847. [CrossRef] [PubMed]

7. Shibata, S.; Watanabe, T.; Yukawa, Y.; Minakuchi, M.; Shimomura, R.; Mima, T. Effect of transcranial static magnetic stimulation on intracortical excitability in the contralateral primary motor cortex. Neurosci. Lett. 2020, 723, 134871. [CrossRef]

8. Pineda-Pardo, J.A.; Obeso, I.; Guida, P.; Dileone, M.; Strange, B.A.; Obeso, J.A.; Oliviero, A.; Foffani, G. Static magnetic field stimulation of the supplementary motor area modulates resting-state activity and motor behavior. Commun. Biol. $2019,2,397$. [CrossRef]

9. Sheffield, A.; Ahn, S.; Alagapan, S.; Fröhlich, F. Modulating neural oscillations by transcranial static magnetic field stimulation of the dorsolateral prefrontal cortex: A crossover, double-blind, sham-controlled pilot study. Eur. J. Neurosci. 2019, 49, $250-262$. [CrossRef]

10. Takamatsu, Y.; Koganemaru, S.; Watanabe, T.; Shibata, S.; Yukawa, Y.; Minakuchi, M.; Shimomura, R.; Mima, T. Transcranial static magnetic stimulation over the motor cortex can facilitate the contralateral cortical excitability in human. Sci. Rep. 2021, 11, 5370. [CrossRef]

11. Tsuru, D.; Watanabe, T.; Chen, X.; Kubo, N.; Sunagawa, T.; Mima, T.; Kirimoto, H. The effects of transcranial static magnetic fields stimulation over the supplementary motor area on anticipatory postural adjustments. Neurosci. Lett. 2020, 723, 134863. [CrossRef]

12. Nakagawa, K.; Sasaki, A.; Nakazawa, K. Accuracy in Pinch Force Control Can Be Altered by Static Magnetic Field Stimulation Over the Primary Motor Cortex. Neuromodul. J. Int. Neuromodul. Soc. 2019, 22, 871-876. [CrossRef]

13. Kirimoto, H.; Watanabe, T.; Kubo, N.; Date, S.; Sunagawa, T.; Mima, T.; Ogata, K.; Nakazono, H.; Tobimatsu, S.; Oliviero, A. Influence of Static Magnetic Field Stimulation on the Accuracy of Tachystoscopically Presented Line Bisection. Brain Sci. 2020, 10, 1006. [CrossRef]

14. Nojima, I.; Watanabe, T.; Gyoda, T.; Sugata, H.; Ikeda, T.; Mima, T. Transcranial static magnetic stimulation over the primary motor cortex alters sequential implicit motor learning. Neurosci. Lett. 2019, 696, 33-37. [CrossRef] [PubMed]

15. Lacroix, A.; Proulx-Bégin, L.; Hamel, R.; De Beaumont, L.; Bernier, P.M.; Lepage, J.F. Static magnetic stimulation of the primary motor cortex impairs online but not offline motor sequence learning. Sci. Rep. 2019, 9, 9886. [CrossRef]

16. Kufner, M.; Brückner, S.; Kammer, T. No modulatory effects by transcranial static magnetic field stimulation of human motor and somatosensory cortex. Brain Stimul. 2017, 10, 703-710. [CrossRef] [PubMed]

17. Lorenz, S.; Alex, B.; Kammer, T. Ten minutes of transcranial static magnetic field stimulation does not reliably modulate motor cortex excitability. PLoS ONE 2020, 15, e0233614. [CrossRef]

18. Spillane, N.S.; Smith, G.T.; Kahler, C.W. Impulsivity-like traits and smoking behavior in college students. Addict. Behav. 2010, 35, 700-705. [CrossRef]

19. Bénard, M.; Bellisle, F.; Kesse-Guyot, E.; Julia, C.; Andreeva, V.A.; Etilé, F.; Reach, G.; Dechelotte, P.; Tavolacci, M.P.; Hercberg, S.; et al. Impulsivity is associated with food intake, snacking, and eating disorders in a general population. Am. J. Clin. Nutr. 2019, 109, 117-126. [CrossRef] [PubMed]

20. Perry, J.L.; Carroll, M.E. The role of impulsive behavior in drug abuse. Psychopharmacology 2008, 200, 1-26. [CrossRef]

21. Watanabe, T.; Ishida, K.; Tanabe, S.; Nojima, I. Preparatory state and postural adjustment strategies for choice reaction step initiation. Neuroscience 2016, 332, 140-148. [CrossRef]

22. Watanabe, T.; Saito, K.; Ishida, K.; Tanabe, S.; Nojima, I. Auditory stimulus has a larger effect on anticipatory postural adjustments in older than young adults during choice step reaction. Eur. J. Appl. Physiol. 2017, 117, 2409-2423. [CrossRef] [PubMed]

23. Watanabe, T.; Tsutou, K.; Saito, K.; Ishida, K.; Tanabe, S.; Nojima, I. Performance monitoring and response conflict resolution associated with choice stepping reaction tasks. Exp. Brain Res. 2016, 234, 3355-3365. [CrossRef] [PubMed]

24. Allom, V.; Mullan, B.; Hagger, M. Does inhibitory control training improve health behaviour? A meta-analysis. Health Psychol. Rev. 2016, 10, 168-186. [CrossRef]

25. Kawashima, R.; Satoh, K.; Itoh, H.; Ono, S.; Furumoto, S.; Gotoh, R.; Koyama, M.; Yoshioka, S.; Takahashi, T.; Takahashi, K.; et al. Functional anatomy of GO/NO-GO discrimination and response selection-A PET study in man. Brain Res. 1996, 728, 79-89. [PubMed]

26. Del Felice, A.; Bellamoli, E.; Formaggio, E.; Manganotti, P.; Masiero, S.; Cuoghi, G.; Rimondo, C.; Genetti, B.; Sperotto, M.; Corso, F.; et al. Neurophysiological, psychological and behavioural correlates of rTMS treatment in alcohol dependence. Drug Alcohol Depend. 2016, 158, 147-153. [CrossRef]

27. Boggio, P.S.; Bermpohl, F.; Vergara, A.O.; Muniz, A.L.; Nahas, F.H.; Leme, P.B.; Rigonatti, S.P.; Fregni, F. Go-no-go task performance improvement after anodal transcranial DC stimulation of the left dorsolateral prefrontal cortex in major depression. J. Affect. Disord. 2007, 101, 91-98. [CrossRef] 
28. Soltaninejad, Z.; Nejati, V.; Ekhtiari, H. Effect of Anodal and Cathodal Transcranial Direct Current Stimulation on DLPFC on Modulation of Inhibitory Control in ADHD. J. Atten. Disord. 2019, 23, 325-332. [CrossRef]

29. Knechtel, L.; Thienel, R.; Cooper, G.; Case, V.; Schall, U. Transcranial direct current stimulation of prefrontal cortex: An auditory event-related potential study in schizophrenia. Neurol. Psychiatry Brain Res. 2014, 20, 102-106. [CrossRef]

30. Nejati, V.; Salehinejad, M.A.; Nitsche, M.A.; Najian, A.; Javadi, A.H. Transcranial Direct Current Stimulation Improves Executive Dysfunctions in ADHD: Implications for Inhibitory Control, Interference Control, Working Memory, and Cognitive Flexibility. J. Atten. Disord. 2020, 24, 1928-1943. [CrossRef]

31. Cosmo, C.; Baptista, A.F.; de Araújo, A.N.; do Rosário, R.S.; Miranda, J.G.; Montoya, P.; de Sena, E.P. A Randomized, Double-Blind, Sham-Controlled Trial of Transcranial Direct Current Stimulation in Attention-Deficit/Hyperactivity Disorder. PLoS ONE 2015, 10, e0135371. [CrossRef] [PubMed]

32. Herremans, S.C.; Vanderhasselt, M.A.; De Raedt, R.; Baeken, C. Reduced intra-individual reaction time variability during a Go-NoGo task in detoxified alcohol-dependent patients after one right-sided dorsolateral prefrontal HF-rTMS session. Alcohol Alcohol. 2013, 48, 552-557. [CrossRef] [PubMed]

33. Schluter, R.S.; van Holst, R.J.; Goudriaan, A.E. Effects of Ten Sessions of High Frequency Repetitive Transcranial Magnetic Stimulation (HF-rTMS) Add-on Treatment on Impulsivity in Alcohol Use Disorder. Front. Neurosci. 2019, 13, 1257. [CrossRef]

34. Rosen, A.D. Mechanism of action of moderate-intensity static magnetic fields on biological systems. Cell Biochem. Biophys. 2003, 39, 163-173. [CrossRef]

35. Rosen, A.D. Inhibition of calcium channel activation in GH3 cells by static magnetic fields. Biochim. Biophys. Acta 1996, 1282, 149-155. [CrossRef]

36. Albuquerque, W.W.; Costa, R.M.; de Salazar e Fernandes, T.; Porto, A.L. Evidences of the static magnetic field influence on cellular systems. Prog. Biophys. Mol. Biol. 2016, 121, 16-28. [CrossRef] [PubMed]

37. Beeli, G.; Casutt, G.; Baumgartner, T.; Jäncke, L. Modulating presence and impulsiveness by external stimulation of the brain. Behav. Brain Funct. BBF 2008, 4, 33. [CrossRef]

38. Nieratschker, V.; Kiefer, C.; Giel, K.; Krüger, R.; Plewnia, C. The COMT Val/Met polymorphism modulates effects of tDCS on response inhibition. Brain Stimul. 2015, 8, 283-288. [CrossRef]

39. Tsujimoto, S.; Kuwajima, M.; Sawaguchi, T. Developmental fractionation of working memory and response inhibition during childhood. Exp. Psychol. 2007, 54, 30-37. [CrossRef]

40. Jeffreys, H. The Theory of Probability; Oxford University Press: Oxford, UK, 1961.

41. Gaskill, B.N.; Garner, J.P. Power to the People: Power, Negative Results and Sample Size. J. Am. Assoc. Lab. Anim. Sci. JAALAS 2020, 59, 9-16. [CrossRef]

42. Vieira, P.G.; Krause, M.R.; Pack, C.C. tACS entrains neural activity while somatosensory input is blocked. PLoS Biol. 2020, 18, e3000834. [CrossRef]

43. Lakens, D. Equivalence Tests: A Practical Primer for t Tests, Correlations, and Meta-Analyses. Soc. Psychol. Personal. Sci. 2017, 8, 355-362. [CrossRef] [PubMed]

44. Vanderhasselt, M.A.; De Raedt, R.; Baeken, C.; Leyman, L.; D'Haenen, H. The influence of rTMS over the left dorsolateral prefrontal cortex on Stroop task performance. Exp. Brain Res. 2006, 169, 279-282. [CrossRef]

45. Nejati, V.; Salehinejad, M.A.; Nitsche, M.A. Interaction of the Left Dorsolateral Prefrontal Cortex (l-DLPFC) and Right Orbitofrontal Cortex (OFC) in Hot and Cold Executive Functions: Evidence from Transcranial Direct Current Stimulation (tDCS). Neuroscience 2018, 369, 109-123. [CrossRef]

46. Cunillera, T.; Brignani, D.; Cucurell, D.; Fuentemilla, L.; Miniussi, C. The right inferior frontal cortex in response inhibition: A tDCS-ERP co-registration study. Neuroimage 2016, 140, 66-75. [CrossRef]

47. Landis, J.R.; Koch, G.G. The measurement of observer agreement for categorical data. Biometrics 1977, 33, 159-174. [CrossRef] [PubMed]

48. Band, G.P.; Ridderinkhof, K.R.; van der Molen, M.W. Speed-accuracy modulation in case of conflict: The roles of activation and inhibition. Psychol. Res. 2003, 67, 266-279. [CrossRef]

49. Brunoni, A.R.; Vanderhasselt, M.A. Working memory improvement with non-invasive brain stimulation of the dorsolateral prefrontal cortex: A systematic review and meta-analysis. Brain Cogn. 2014, 86, 1-9. [CrossRef] [PubMed]

50. Dedoncker, J.; Brunoni, A.R.; Baeken, C.; Vanderhasselt, M.A. A Systematic Review and Meta-Analysis of the Effects of Transcranial Direct Current Stimulation (tDCS) Over the Dorsolateral Prefrontal Cortex in Healthy and Neuropsychiatric Samples: Influence of Stimulation Parameters. Brain Stimul. 2016, 9, 501-517. [CrossRef]

51. Brevet-Aeby, C.; Mondino, M.; Poulet, E.; Brunelin, J. Three repeated sessions of transcranial random noise stimulation (tRNS) leads to long-term effects on reaction time in the Go/No Go task. Neurophysiol. Clin. 2019, 49, 27-32. [CrossRef]

52. Rivadulla, C.; Foffani, G.; Oliviero, A. Magnetic field strength and reproducibility of neodymium magnets useful for transcranial static magnetic field stimulation of the human cortex. Neuromodul. J. Int. Neuromodul. Soc. 2014, 17, 438-441; discussion 432-441. [CrossRef]

53. Hill, A.T.; Fitzgerald, P.B.; Hoy, K.E. Effects of Anodal Transcranial Direct Current Stimulation on Working Memory: A Systematic Review and Meta-Analysis of Findings from Healthy and Neuropsychiatric Populations. Brain Stimul. 2016, 9, 197-208. [CrossRef] [PubMed] 
54. Horvath, J.C.; Forte, J.D.; Carter, O. Quantitative Review Finds No Evidence of Cognitive Effects in Healthy Populations from Single-session Transcranial Direct Current Stimulation (tDCS). Brain Stimul. 2015, 8, 535-550. [CrossRef] [PubMed]

55. Oliviero, A.; Carrasco-López, M.C.; Campolo, M.; Perez-Borrego, Y.A.; Soto-León, V.; Gonzalez-Rosa, J.J.; Higuero, A.M.; Strange, B.A.; Abad-Rodriguez, J.; Foffani, G. Safety Study of Transcranial Static Magnetic Field Stimulation (tSMS) of the Human Cortex. Brain Stimul. 2015, 8, 481-485. [CrossRef]

56. Aron, A.R.; Robbins, T.W.; Poldrack, R.A. Inhibition and the right inferior frontal cortex. Trends Cogn. Sci. 2004, 8, 170-177. [CrossRef] [PubMed]

57. Tabu, H.; Mima, T.; Aso, T.; Takahashi, R.; Fukuyama, H. Functional relevance of pre-supplementary motor areas for the choice to stop during Stop signal task. Neurosci. Res. 2011, 70, 277-284. [CrossRef]

58. Tabu, H.; Mima, T.; Aso, T.; Takahashi, R.; Fukuyama, H. Common inhibitory prefrontal activation during inhibition of hand and foot responses. Neuroimage 2012, 59, 3373-3378. [CrossRef]

59. Begum, T.; Mima, T.; Oga, T.; Hara, H.; Satow, T.; Ikeda, A.; Nagamine, T.; Fukuyama, H.; Shibasaki, H. Cortical mechanisms of unilateral voluntary motor inhibition in humans. Neurosci. Res. 2005, 53, 428-435. [CrossRef]

60. Hughes, M.E.; Budd, T.W.; Fulham, W.R.; Lancaster, S.; Woods, W.; Rossell, S.L.; Michie, P.T. Sustained brain activation supporting stop-signal task performance. Eur. J. Neurosci. 2014, 39, 1363-1369. [CrossRef]

61. Chambers, C.D.; Bellgrove, M.A.; Stokes, M.G.; Henderson, T.R.; Garavan, H.; Robertson, I.H.; Morris, A.P.; Mattingley, J.B. Executive "brake failure" following deactivation of human frontal lobe. J. Cogn. Neurosci. 2006, 18, 444-455. [CrossRef]

62. Verbruggen, F.; Aron, A.R.; Stevens, M.A.; Chambers, C.D. Theta burst stimulation dissociates attention and action updating in human inferior frontal cortex. Proc. Natl. Acad. Sci. USA 2010, 107, 13966-13971. [CrossRef]

63. Dambacher, F.; Schuhmann, T.; Lobbestael, J.; Arntz, A.; Brugman, S.; Sack, A.T. No Effects of Bilateral tDCS over Inferior Frontal Gyrus on Response Inhibition and Aggression. PLOS ONE 2015, 10, e0132170. [CrossRef] [PubMed]

64. Loftus, A.M.; Yalcin, O.; Baughman, F.D.; Vanman, E.J.; Hagger, M.S. The impact of transcranial direct current stimulation on inhibitory control in young adults. Brain Behav. 2015, 5, e00332. [CrossRef] [PubMed]

65. Cunillera, T.; Fuentemilla, L.; Brignani, D.; Cucurell, D.; Miniussi, C. A simultaneous modulation of reactive and proactive inhibition processes by anodal tDCS on the right inferior frontal cortex. PLoS ONE 2014, 9, e113537. [CrossRef] [PubMed]

66. Pellegrini, M.; Zoghi, M.; Jaberzadeh, S. Cluster analysis and subgrouping to investigate inter-individual variability to noninvasive brain stimulation: A systematic review. Rev. Neurosci. 2018, 29, 675-697. [CrossRef] [PubMed]

67. López-Alonso, V.; Cheeran, B.; Río-Rodríguez, D.; Fernández-Del-Olmo, M. Inter-individual variability in response to noninvasive brain stimulation paradigms. Brain Stimul. 2014, 7, 372-380. [CrossRef] [PubMed] 